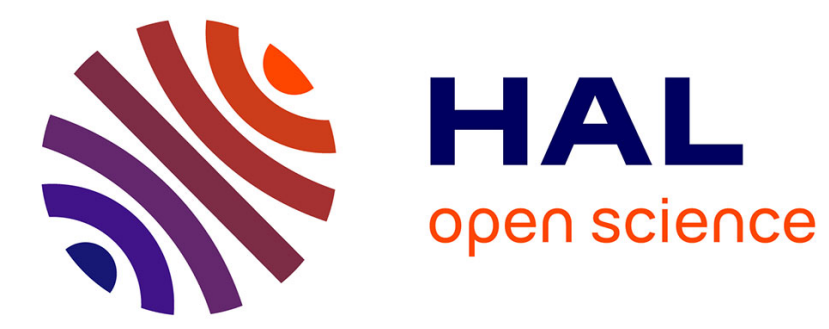

\title{
SIMULATING A MULTIPRODUCT BARTER EXCHANGE ECONOMY
}

Daniel Levy, Mark Bergen

\section{To cite this version:}

Daniel Levy, Mark Bergen. SIMULATING A MULTIPRODUCT BARTER EXCHANGE ECONOMY. Economic Inquiry, 1993, 31 (2), pp.314-321. 10.1111/j.1465-7295.1993.tb00885.x . hal02382710

\section{HAL Id: hal-02382710 https://hal.science/hal-02382710}

Submitted on 27 Nov 2019

HAL is a multi-disciplinary open access archive for the deposit and dissemination of scientific research documents, whether they are published or not. The documents may come from teaching and research institutions in France or abroad, or from public or private research centers.
L'archive ouverte pluridisciplinaire HAL, est destinée au dépôt et à la diffusion de documents scientifiques de niveau recherche, publiés ou non, émanant des établissements d'enseignement et de recherche français ou étrangers, des laboratoires publics ou privés. 
Forthcoming

Economic Inquiry, 1993

\section{Simulating a Multiproduct Barter Exchange Economy}

Daniel Levy

and

Mark Bergen*

August 1992 
Journal of Economic Literature Codes: A22, E40

Simulating a Multiproduct Barter Exchange Economy

\begin{abstract}
We describe a multiproduct barter trading experiment in which students exchange real goods in an open market based on their own personal preference. The experiment is designed for simulating a pure exchange market in order to demonstrate the role of money and its functions in real economies by showing the limitations and inefficiencies of the traditional barter economy. In addition, the simulation is very effective in highlighting some of the key features that an object that serves as money needs to possess in order to function as an efficient medium of exchange, unit of account, and store of value.
\end{abstract}

Daniel Levy

Department of Economics

Union College

Schenectady, NY 12308

and

Mark Bergen

Graduate School of Business

University of Chicago

Chicago, IL 60637 


\section{INTRODUCTION}

As a research tool, experimental economics is a very useful device for studying many issues in economics, including choice theory, industrial organization, public finance, financial markets, etc. However, by its nature, most of the classroom applications are concentrated in simulating microeconomic markets for specific goods or assets. For example, various versions of "double-oral auction" type experiments popularized by Smith [1962; 1965] and his students are designed to demonstrate supply-demand interactions in generating competitive equilibria, and to show the effects of various market organizations and regulations on competitive equilibrium outcomes. Similarly, various asset market experiments usually demonstrate different aspects of asset market organizations and operations, such as asset valuation, informational efficiency, individual rationality, etc.

In this paper we describe a multiproduct barter trading simulation experiment which we have successfully used since 1988 at the University of Minnesota, University of California/Irvine, Pepperdine University, University of Chicago, and Union College. The experiment can be used in introductory and intermediate macroeconomic classes as well as in more advanced classes such as money and banking. Despite the prevalence of various forms of barter in today's economies, most students are not aware of barter trade as a mechanism for exchange. ${ }^{1}$ Experimenting with barter exchange provides a useful starting point for a classroom discussion of money and its role in the economy. Our implementation of the experiment is specifically designed for demonstrating limitations and inefficiencies of the traditional barter economy and for emphasizing the role of money as a medium of exchange, unit of account, and store of value. ${ }^{2}$ In addition, this experiment helps in demonstrating some of the key features that an object that serves as money should possess in order to function effectively and efficiently.

In the experiment students exchange real goods (various food items) in an open, pure-exchange market, without any restrictions. Unlike many experiments that last weeks 
and sometimes even an entire term, this experiment is not time consuming, and can be easily conducted in one 90-minute session, including the follow-up discussion. Also, unlike the experiments in which participants' preferences are set exogenously by the instructors, here the students are acting based on their own personal preferences, and their trade objects are real goods, not plastic chips, or index cards. This makes the experiment very realistic and life-like. ${ }^{3}$

\section{DESCRIPTION OF THE EXPERIMENT}

In principle the experiment can be conducted after a regular classroom lecture on "Money and its Role in the Economy". However, we find that students act more naturally, and also learn and enjoy more, when it is conducted before the lecture. During the lecture prior to the experiment day, we announce in class that we are preparing a surprise for the next meeting: we will serve a food during regular lecture meeting and instead of talking economics, they will eat a nice breakfast/lunch/dinner (depending on the class meeting time). If the class meeting time falls outside ordinary dining hours, then promising every student 3 or $5 \%$ of the final course grade just for coming hungry to the classroom is always

sufficient for a successful simulation of the experiment in class. ${ }^{4}$ Class size usually is not a problem. We have simulated barter economies in classes with as few as 7 students and as many as 35 students.

The experiment starts by giving each student (or alternatively each group of 3-5 students) an initial endowment of various food items. The example presented in Table I provides a list of some of the food items that can be distributed in a class of 25 students along with initial endowment allocations. We have used similar menus for various afternoon and evening classes. The initial endowments should be distributed so that complementary products will not end up in the hands of the same group of students or the same individual. This guarantees that some exchange will take place before the food is 
consumed. For example, if one student gets a two-liter bottle of soft drink, then some other student should get the plastic cups. The total amount of food distributed should be sufficient for feeding the entire class, otherwise the students leave the classroom unhappy.

The students are told that they can consume whatever they wish, and that there is enough food for everybody in the classroom. We also emphasize that their initial wealth allocation is such that at least some of them will have to exchange part of their supply for other items in order to consume it. They are allowed to make whatever exchange they desire following their individual or group preferences, the exchange price is negotiable, and should be determined by participating parties. Although we do not really talk about ideal menu content, most students usually attempt to achieve a balanced meal through barter trade, that is, a meal that contains a main dish and/or vegetable salad, a drink, and some desert.

There are no restrictions on exchange and any exchange is valid. The students are not allowed to buy or sell on credit. That is, they cannot get pizza today and tell their friends that they will pay for it tomorrow. Also, there is no storage technology, so the students must return any unused items to the instructor. This guarantees that the students will exchange at least some of their commodities, as they will not be able to just eat whatever they like and take home the leftover. Each student or group of students is given a simple form in which they are asked to record their endowment along with their final consumption bundle, every single transaction they make, which goods were involved in the exchange, what were the quantities, and what was the exchange rate. An example of such a form is provided in Table II. This information is later used in the follow-up discussion.

Physically, the students are asked to form a circle with their chairs (if the classroom setup permits), and clearly display whatever they wish to exchange. In order to initiate an exchange, they can either go from chair to chair with their supplies and offer exchange prices, or they can negotiate right from their seats. The entire simulation including the 
dining time, usually takes about $45-50$ minutes. If time is a concern, the experiment can be shortened by reducing the number of groups. It can be further shortened by reducing the number of commodities used.

\section{FOLLOW-UP DISCUSSION}

Following the simulation, the class discussion usually focuses on their impressions from the experiment. The students are asked to freely describe their observations about what they saw, whether they have noticed anything unique, unusual, or different from ordinary market mechanisms, and what lessons, if any, they have learned from the experiment. While discussing the students comments, we usually try to lead the discussion towards specific issues on money, and its role in the economy in a more structured format.

For example, in our introductory macro classes, we initially focus students' attention on the problems caused by the lack of a commonly acceptable medium of exchange, unit of account, and store of value. Afterwards we try to focus on the importance of the features that an object that serves as money should possess in order to function effectively and efficiently. These features include homogeneity, divisibility, storability, durability, and scarcity. ${ }^{5}$ Finally, we often get to one or two additional issues, such as efficiency versus equity, money's contribution to social welfare by promoting specialization, etc.

This follow up discussion usually lasts about 40 minutes. The discussion can be shortened by reducing the number of topics discussed or by avoiding in-depth discussion of some issues. For example, in advanced classes (like money and banking) the instructor may choose to focus on the functions of money. The following list is a sample of some of the issues and topics raised and discussed. The list is not exhaustive, and instructors may choose to discuss other aspects or implications of the experiment following their own interest. 


\section{Functions of Money}

Money as a Medium of Exchange. After noting that in this classroom economy we had no real money, we ask the students to identify any one object or food item that played in the experiment a role similar to the role money plays in exchanges that take place in real economies. The problem of double coincidence of wants caused by the lack of a commonly accepted medium of exchange is one of the central problems of barter economy. In the experiment we demonstrate this problem by allocating endowments so that some of the trades will benefit one group but not another, and so no transaction will take place between these groups. For example, according to the sample menu presented in Table I, Groups 3 and 7 probably will not trade directly because of the lack of double coincidence of wants.

Money as an Unit of account. After collecting the Transaction Record's form from the students, we ask them questions like: What is the value of a commodity in a barter economy? What was the market price of a slice of pizza? This leads to discussions on the multiplicity of prices in a barter economy. We also try to see whether the prices that were set in various transactions are consistent with each other. Obviously, they are rarely consistent. The discussions about price multiplicity and the lack of unit of account usually leads to discussions about value. Questions of the type: "how do you know that the price you paid is a good price?," or, "how would you define a good price in this economy?," or "what determines the exchange rate in this barter economy?," always lead to interesting discussions about individual preferences, demand-supply interaction, subjective marginal rates of substitution, etc. ${ }^{6}$ Then we go back to the issue of lack of consistency of the prices and discuss the observed price inconsistency by relating it to the issue of individual preferences. 
Money as a Store of Value. Because the experiment only lasts 40-50 minutes, highlighting this role of money in our experimental setup is not easy. We use (partially melted) ice cubes to demonstrate the importance of this function of money. As the trade progresses, the ice melts almost completely. Consequently, it starts to loose its usefulness, and students often refuse to accept it in exchange, or they only offer very low price for it. This shows the students that an object must offer a good store of value in order to function as money.

\section{Features of Money}

To highlight the main features that an object that serves as money should possess, we ask the students to identify one commodity that could serve as a commodity money? While in principle any commodity could serve as money, some commodities would make a "better" commodity money than others. For example, students always complain if their endowment includes something like Organic Nasoya Well Water Tofu, since usually nobody is willing to exchange anything for it in this experimental setup. ${ }^{7}$ Introduction of the concept of commodity money makes the following discussion of features of money tangible to students that just participated in barter exchange.

Homogeneity. By distributing close, but not perfect substitutes as a part of initial endowments, we demonstrate the importance of homogeneity for an object in order to serve as a commonly acceptable medium of exchange. For example, a student would refuse to accept a Tuna-Salad sandwich and instead would demand Cheese or Ham sandwich. We obviously do not have such problems with modern money since modern money is homogeneous. 
Divisibility. This is another important feature that modern money possesses. In the experiment we demonstrate this feature by distributing a food item which is not easily divisible, yet it is consumable: two liter bottled soft drinks. By limiting the number of plastic cups available in the market, we make some of the bottled soft drinks indivisible. ${ }^{8}$ Indivisibility makes the soft drinks a very inefficient medium of exchange.

Durability and Storability. Because the experiment is conducted in a classroom, and it only lasts about 45-50 minutes, it was tricky to find a commodity which would be hard to store or which would not be durable enough to last such a short time. It turns out that ice cubes can serve this purpose as well. At the beginning of the trade, fresh ice cubes are usually accepted in exchange for other food items. However, as the ice starts to melt, it becomes useless, and so students refuse to accept it. Melted ice is almost impossible to store in the classroom setup since we distribute the ice cubes in plastic bags.

Scarcity. We demonstrate this important feature of money by simply including a particular commodity in every group's endowment bundle. ${ }^{9}$ It is not surprising that the students always refuse to exchange anything for that item. 10

\section{Efficiency versus Equity}

During the simulation some students, especially those with relatively poor initial endowments (like groups 4 or 5 in the example of Table I), often express frustration and complain about an unfair allocation of the initial endowments, without noticing that they are making normative statements. Sometimes, in order to give these students a feeling of fairness, or in order to demonstrate a need of some kind of income redistribution schemes in real economies, we intervene in the market in the middle of trade, and declare that the government has decided to follow a Robin Hood kind of policy by taxing the rich and 
giving to the poor. The policy is implemented by simply taking some food items from rich groups or individuals and giving them to the poor. The reaction of various groups or individuals to this type of policy quite often leads to interesting discussions about fairness, fair allocation mechanisms, the need for government intervention, income redistribution schemes, etc. ${ }^{11}$ This gives us an opportunity to discuss the ability of money to enhance the efficiency of the market mechanism against its inability to enhance equity along the lines presented by Okun [1978]. Since the students participating in this experiment naturally are concerned with equity, the act of taxing helps us to motivate this discussion.

\section{$\underline{\text { Information and Identification Cost }}$}

The experiment could be further deepened by demonstrating the idea that it is the costliness of the information about the attributes of various goods that induces the use of money as a medium of exchange, as discussed in Alchian [1977], and Brunner and Meltzer [1971]. ${ }^{12}$ Product identification can be made difficult and costly by using generic (not brand name) or homemade products as in the endowment of Group 1 in Table I.

Obviously, students have less information about the attributes of such products than brand name goods which they often consume, and consequently will be more reluctant to accept them in exchange.

\section{Other Issues and Extensions}

Other related issues that we often discuss include: money's contribution to social welfare by promoting specialization; historical episodes of bartering; possible emergence of a single commodity as "money" in barter economies, like cigarettes in the P.O.W. camp as discussed in Radford [1945]; used goods market; rental goods market, etc. ${ }^{13}$ 
One shortcoming of the experiment for the purpose of demonstrating the limitations of a barter economy is the fact that the students eventually make enough exchanges to have a balanced meal, although some of the exchanges are complicated and often involve 3-4 groups of students and 5-8 commodities. This is so because in our setup everything is portable, and information flow is perfect. Therefore, our setup lacks two important difficulties of real barter economies. In addition, in our experiment no storage technology is available, and since we collect any leftovers, students may be exchanging things that perhaps they would prefer to keep. The information flow can be made imperfect by scattering the students in a large auditorium, a football field, or even in several classrooms. The portability problem can be created by imposing restrictions on the market mechanism.

With some modifications, the experiment can also be used to complement classroom discussions on other economic concepts and issues such as monopoly, the fairness of market mechanisms and resulting allocations, supply and demand interaction, taxation and income distribution (as described in the Efficiency versus Equity section), market failures and the need for government intervention, the effects of various regulations on market activities, the role of marketing in improving transaction efficiencies, etc. Also, there may be a way to introduce production technology in this experiment, along the lines suggested by Karpoff [1984]. 


\section{REFERENCES}

Alchian, Armen A. "Why Money?" Journal of Money, Credit, and Banking, February 1977, 111-40.

Brunner, Karl and Allan H. Meltzer. "The Uses of Money: Money in the Theory of an Exchange Economy.” American Economic Review, December 1971, 784-805.

Fisher, Bart S. "Introduction," in Barter in the World Economy, edited by Bart S. Fisher and Kathleen M. Harte. New York: Praeger Publishers, 1985, 1-5.

Higgiston, James. "Domestic Barter," in Barter in the World Economy, edited by Bart S. Fisher and Kathleen M. Harte. New York: Praeger Publishers, 1985, 156-67.

Kaikati, Jack G. "Marketing without Exchange of Money.” Harvard Business Review, November/December 1982, 72-74.

Karpoff, Jonathan M. "Barter Trading as a Microeconomics Teaching Device.” Journal of Economic Education, Summer 1984, 226-36.

Okun, Arthur. Equity versus Efficiency: the Big Tradeoff. Washington, DC: The Brookings Institution, 1978.

Radford, R. A. "The Economic Organization of a P.O.W. Camp." Economica, November 1945, 189-201. 
Smith, Vernon L. "An Experimental Study of Competitive Market Behavior.” Journal of Political Economy, April 1962, 111-37. . "Experimental Auction Markets and the Walrasian Hypothesis."

Journal of Political Economy, August 1965, 387-93.

U.S. International Trade Commission. Analysis of Recent Trends in U.S. Countertrade. USITC Publication No. 1237, 1982. 


\section{FOOTNOTES}

* Assistant Professor, Union College, and Assistant Professor, Graduate School of Business, University of Chicago. All correspondence should be addressed to the first author. We thank an anonymous referee for useful comments and suggestions. We owe special thanks to the Teaching Tools section editor, Robert L. Moore for his guidance and many specific helpful comments, which greatly improved the manuscript. We also thank Hal Fried, Doug Klein, Eshi Motahar, Bruce Reynolds, Shelton Schmidt, and James Stodder for useful discussions and suggestions. The second author acknowledges financial support of the Bozell, Jacobs, Kenyon, and Eckhardt Endowment Fund at the Graduate School of Business, University of Chicago. All the errors are ours.

1. Modern versions of barter include countertrade, counterpurchase, compensation, import entitlement programs, offsets, clearing arrangements, switch trading, etc. Some of these forms of barter are an alternative form of financing for deals that would otherwise not have taken place. These forms of barter are growing phenomena in the world economy, and according to the USITC [1982] estimates, may account for 20-30\% of world trade, and 5-10\% of domestic U.S. commerce. Other estimates cited in Higgiston [1985] are in range $3-25 \%$ of the GNP. As Kaikati [1982] suggests, one cause of domestic barter expansion is the increase in popularity of barter clubs.

2. As Fisher [1985, 5] notes, "the principle of reciprocal exchange of goods, of giving and taking, appears to be deeply rooted in human nature. Commerce in the form of regular acts of exchange appears even in the lowest level of primitive peoples. Variations on the direct exchange of goods against goods include 'silent trade,' or dumb barter, with neither party holding any communications with the other, and the 'gift-exchange,' in which the 
transaction takes the form of present and counter-present."

3. An interesting experiment suggested by Karpoff [1984] is somewhat similar to our experiment, but there are some differences. Unlike our experiment, Karpoff's experiment is designed as a microeconomic teaching device. Also, his experiment simulates a twogood barter economy, whereas we often use about 20 (and sometimes even more) different commodities. Finally, unlike our experiment, Karpoff's experiment is designed to last several weeks. The use of many commodities makes this simulation experiment more lifelike. However, as Karpoff [1984] suggests, use of many commodities also increases the complexity of such experiments.

4. This will have no effect on course grades' distribution, as usually all the students show up to this session.

5. This experiment is not well suited for demonstrating the importance of an additional feature that modern money possess, namely portability, as the experiment is conducted in a classroom.

6. We have frequently encountered cases in which some students respond with astonishment when they see the price their classmates paid for some commodities. Reactions like, "What? You gave entire bottle of Coca Cola for a plastic cup? Are you nuts?" are very common.

7. According to the producers of the TV game, Jeopardy, the correct response to the statement "This is the most hated food in America," is "What is Tofu?"

8. We owe this idea to Hal Fried. 
9. In the example of Table I, plastic spoon is such a commodity. Note that in this example lack of scarcity of spoons is not universal. That is, the amount of spoons available is not unlimited. In this setup spoons have no transaction value simply because nobody needs more than one spoon to eat a lunch.

10. In one occasion, the student that was endowed with napkins decided to ask in exchange for them what many students thought was ridiculously high price. One student got really mad, went to the restroom and brought paper towel to use as napkins. As soon as other students saw that, they did the same. The napkins' purchasing power instantaneously dropped to zero, since it was not scarce anymore.

11. We had an opportunity in one occasion to see a spontaneous tax evasion attempt in response to our implementation of income redistribution scheme: after declaring that we are taxing the rich and giving it to the poor, we took one half of ice-cream container from a "rich" student and gave it to the "poor. There was another lucky student in class that was endowed with ice-cream and as soon as he saw what we did, he spontaneously took the ice-cream container and hid it underneath his desk, and he was not joking!

12. We thank the referee for suggesting this idea.

13. In one of the recent experiments we witnessed an emergence of "used cups" market as well as "cups for rental" business. We have created a shortage of cups by distributing only five cups in a class of 14 students. This made 2-liter bottled soft drinks indivisible. To overcome the problem, the students rented used cups in two occasions. Afterwards, some students actually bought used cups. 
Table I. A Menu and Initial Endowment Allocation for a 25 Student Class

Group No. 1

2 Tuna Salad Sandwiches

2 Ham Sandwiches

3 Servings of homemade lasagna

3 Plastic Spoons

Group No. 3

2 Chef's Salads

3 Plastic Spoons

Group No. 5

Ice Cubes in a Plastic Bag

Salad Dressing (24 Servings)

Cream Cheese (6 packs, 8 oz each)

3 Plastic Spoons

Group No. 7

2 Chef's Salads

3 Two Liter Diet Coca-Cola

3 Two Liter Coca-Cola Classic

3 Plastic Spoons
Group No. 2

Häagen-Dazs ice cream, one quart

16oz Organic Nasoya Well Water Tofu

3 Plastic Spoons

Group No. 4

Plastic Plates (25)

Plastic Knives (25), Spoons (3), and Forks (25)

Oreo Cookies

\section{Group No. 6}

8 Bagels (various tastes)

Plastic Cups (10)

3 Plastic Spoons

\section{Group No. 8}

Napkins (pack of 50)

Domino's Pizza (8 Slice Pie)

4 Plastic Spoons 
Table II. Transactions' Record Form

Name/s of the student/s:

Endowment:

Final Consumption:

Leftover:
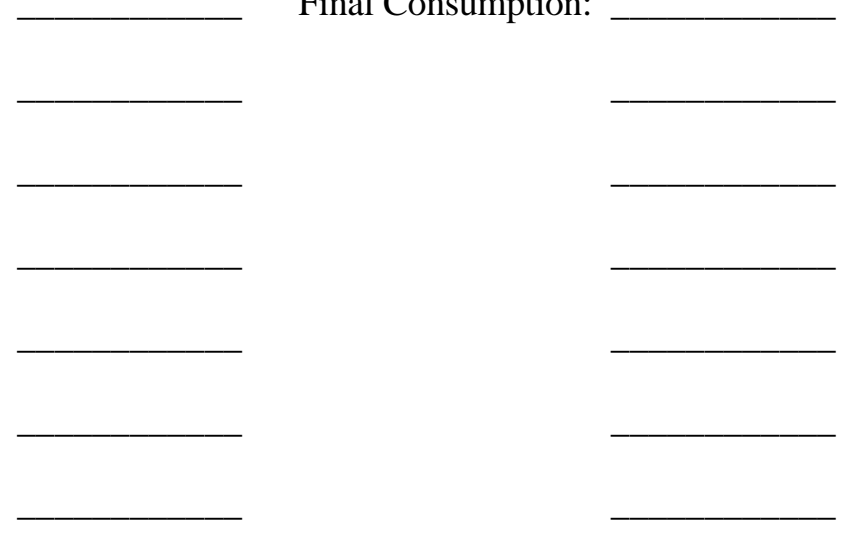

Transactions List:

\begin{tabular}{lll}
\hline $\begin{array}{l}\text { Type and Quantity } \\
\text { of the Good Sold }\end{array}$ & $\begin{array}{l}\text { Type and Quantity } \\
\text { of the Good Bought }\end{array}$ & The Exchange Rate \\
\hline
\end{tabular}

1.

2.

3.

4.

5.

6.

7.

8. 